\title{
Effects of brain polarization on reaction times and pinch force in chronic stroke
}

\author{
Friedhelm C Hummel ${ }^{1,2}$, Bernhard Voller ${ }^{1}$, Pablo Celnik ${ }^{1}$, Agnes Floel ${ }^{1}$, \\ Pascal Giraux ${ }^{1}$, Christian Gerloff ${ }^{2}$ and Leonardo G Cohen*1
}

\begin{abstract}
Address: ${ }^{1}$ Human Cortical Physiology Section and Stroke Neurorehabilitation Clinic, National Institute of Neurological Disorders and Stroke, National Institutes of Health, Bethesda, MD 20892, USA and 2Brain Imaging and Neurostimulation Lab, Department of Neurology, University Medical Center Hamburg-Eppendorf, Martinistr. 52, 20246 Hamburg, Germany

Email: Friedhelm C Hummel - f.hummel@uke.uni-hamburg.de; Bernhard Voller - bernhard.voller@meduniwien.ac.at; Pablo Celnik - CelnikP@ninds.nih.gov; Agnes Floel - floeel@uni-muenster.de; Pascal Giraux - pascal.giraux@univ-st-etienne.fr; Christian Gerloff - gerloff@uke.uni-hamburg.de; Leonardo G Cohen* - cohenl@ninds.nih.gov

* Corresponding author
\end{abstract}

Published: 03 November 2006

BMC Neuroscience 2006, 7:73 doi:10.1/86/147/-2202-7-73
Received: 10 August 2006

Accepted: 03 November 2006

This article is available from: http://www.biomedcentral.com/I47/-2202/7/73

(c) 2006 Hummel et al; licensee BioMed Central Ltd.

This is an Open Access article distributed under the terms of the Creative Commons Attribution License (http://creativecommons.org/licenses/by/2.0), which permits unrestricted use, distribution, and reproduction in any medium, provided the original work is properly cited.

\begin{abstract}
Background: Previous studies showed that anodal transcranial DC stimulation (tDCS) applied to the primary motor cortex of the affected hemisphere $\left(\mathrm{MI}_{\text {affected hemisphere }}\right)$ after subcortical stroke transiently improves performance of complex tasks that mimic activities of daily living (ADL). It is not known if relatively simpler motor tasks are similarly affected. Here we tested the effects of tDCS on pinch force (PF) and simple reaction time (RT) tasks in patients with chronic stroke in a double-blind cross-over Sham-controlled experimental design.
\end{abstract}

Results: Anodal tDCS shortened reaction times and improved pinch force in the paretic hand relative to Sham stimulation, an effect present in patients with higher impairment.

Conclusion: tDCS of $\mathrm{MI}_{\text {affected hemisphere }}$ can modulate performance of motor tasks simpler than those previously studied, a finding that could potentially benefit patients with relatively higher impairment levels.

\section{Background}

Rehabilitative treatments result in incomplete motor recovery after stroke. Six months after stroke, 65 percent of survivors cannot use their paretic hand into daily living activities to the extent done before [1-5]. Absence or minimal hand movements by four weeks is predictive of poor motor outcome [6] and only a small percentage of patients recover function to the extent of communitymatched healthy subjects [7] resulting in marked difficulties in carrying out activities of daily living (ADL).
Recent studies demonstrated that enhancing activity in motor areas of the affected hemisphere $\left(\mathrm{M} 1_{\text {affected hemi- }}\right.$ sphere) by means of anodal transcranial DC stimulation (tDCS) [8-10] or repetitive transcranial magnetic stimulation (rTMS) [11] results in improvements in performance of complex ADL-like tasks with the paretic hand [12]. The tasks utilized in these studies, including the Jebsen-Taylor test (JTT), are cognitively demanding, only in part preprogrammed, and require complex online updating of sensory information as well as adequate sensorimotor integration for accurate performance [13]. Successful performance of the JTT requires a complex pattern of activa- 
tion of muscles and joints as well as the use of targets and tools [13] and such skilled movements engage an extensive network of brain regions [14-16]. As a consequence, ADL-like tasks included in the JTT can be fully carried out by a minority of stroke patients [6].

At present, it is not known if the beneficial effects of tDCS apply only to complex motor tasks in patients with reduced impairment, capable of performing ADL-like tasks or if it can also benefit performance of simpler motor tasks which can be done by patients with higher impairment levels. In this investigation, we studied the effects of anodal tDCS on performance of motor tasks that predominantly rely on M1 functioning such as maximal pinch force production and a simple reaction time task [17-20]. We hypothesized that noninvasive anodal tDCS $[8,21,22]$ applied to $M 1_{\text {affected hemisphere }}$ would improve reaction time and pinch force compared to Sham stimulation [23] in a group of patients with subcortical stroke. Attention, fatigue and discomfort as possible confounds were evaluated using visual analogue scales [8,10,23-28].

\section{Results}

\section{Psychophysical data}

INTERVENTION $_{(\mathrm{tDCS}}$, Sham) did not influence Attention (tDCS: $6.99 \pm 0.22$; Sham: $6.62 \pm 0.27$ ), Fatigue (tDCS: $7.01 \pm 0.20$; Sham: $7.26 \pm 0.22)$. Discomfort/pain was negligible and comparable in the tDCS $(1.67 \pm 0.14)$ and Sham sessions $(1.20 \pm 0.14$, paired t-test, ns $)$ on a scale of 1 (no discomfort) to 10 (maximal pain). None of the patients were able to distinguish between the tDCS and the Sham sessions.

\section{Effects of anodal $t D C S$ of $M I_{\text {affected hemisphere }}$ on reaction time}

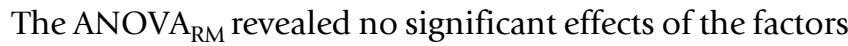
INTERVENTION $_{(\mathrm{tDCS}, \text { Sham) }}(\mathrm{F}[1]=0.02$, ns) or TIME (Base, Post) $(\mathrm{F}[1]=0.07$, ns $)$, but a significant interaction INTERVENTION $_{(\mathrm{tDCS}, \text { Sham })} \times$ TIME $_{(\text {Base, Post })}(\mathrm{F}[1,10]=11.9, \mathrm{p}<$ 0.01; Fig. 1) on RT. Post hoc testing showed that RT experienced a significant reduction with tDCS (from Base $\mathrm{tDCS}_{\mathrm{tDC}}$ $=273.5 \pm 15.4$ msec to Post $_{\mathrm{tDCS}}=256.6 \pm 13.9 \mathrm{msec}, \mathrm{p}<$ 0.05; Fig. 1C) and a nonsignificant trend to lengthening with Sham (from Base Sham $=265.2 \pm 10.7$ msec to Post $_{\text {Sham }}$ $=277.7 \pm 11.6 \mathrm{msec}, \mathrm{p}=0.06)$. Baseline values did not differ significantly between Sham and tDCS. Given the wide inter-patient variability in reaction times (from $187 \mathrm{msec}$ to $364 \mathrm{msec}$ ), post intervention values were also analyzed relative to baseline in each patient (Paired t-test, $\mathrm{p}<0.05$ ). All patients tested showed shortening of RT in the tDCS session (Fig. 1B). Six patients showed slightly longer reaction times with Sham compared to baseline.

Stratification of patients according to impairment levels revealed that tDCS-induced improvement was more pro- nounced in the more impaired group $(\mathrm{RT}=15.0 \pm 3.2 \%$; Fig. 2A) compared to the less impaired group ( $\mathrm{RT}=8.9 \pm$ 3.1\%; Fig. 2A). Correlation analyses showed a nonsignificant trend for more prominent tDCS-induced improvement in RT in patients with lower MRC scores (Spearman's rho [two tailed] $\mathrm{R}^{2}=0.36 ; \mathrm{p}=0.06$ )

\section{Effects of anodal tDCS of $M I_{\text {affected hemisphere }}$ on pinch force} The ANOVA $\mathrm{RM}_{\mathrm{R}}$ revealed no significant effects of the factors INTERVENTION $_{(\mathrm{tDCS}, \text { Sham })}(\mathrm{F}[1]=2.3$, ns $)$ or TIME $_{(\text {Base, }}$ Post $)(F[1]=0.03, \mathrm{~ns})$, but a significant interaction INTERVENTION $_{(\text {tDCS, Sham })} \times$ TIME $_{(\text {Base, Post })}(\mathrm{F}[1,10]=6.1, \mathrm{p}<$ $0.05)$ on PF. Post hoc testing showed that tDCS elicited a nonsignificant trend towards increase in PF with tDCS (from Base $_{\mathrm{tDCS}}=118.8 \pm 23.0 \mathrm{~N}$ to Post tDCS $=124.8 \pm 24.0$ $\mathrm{N} ; \mathrm{p}=0.18$ ) and towards decrease with Sham (from BaseSham $=114.8 \pm 20.4 \mathrm{~N}$ to Post $_{\text {Sham }}=111.2 \pm 19.8 \mathrm{~N} ; \mathrm{p}=$ 0.20 , Fig 3 ) with comparable baselines $(\mathrm{p}=0.51)$. Given the wide inter-patient variability in absolute PF (from $22.1 \mathrm{~N}$ to $249.9 \mathrm{~N}$ ), post intervention values were also expressed relative to baseline in each patient. All patients but one showed improvements in PF with tDCS relative to changes experienced with Sham (Fig. 3A, paired t-test $\mathrm{p}<$ 0.05). Six patients showed a transient slight decrease in force with Sham compared to baseline.

Stratification of patients according to impairment levels revealed that tDCS-induced improvement was more pronounced in the more impaired group ( $\mathrm{PF}=15.7 \pm 4.1 \%$; Fig. 2B) compared to the less impaired group ( $\mathrm{PF}=7.1 \pm$ 2.5\%; Fig. 2B). Correlation analyses did not show a significant correlation between tDCS-induced improvement in PF and the patients' MRC scores (Spearman's rho [two tailed] $\mathrm{R}^{2}=0.08 ; \mathrm{p}=0.27$ ).

\section{Effects of Sham tDCS of $M I_{\text {affected hemisphere }}$ compared to the no stimulation condition}

To determine if relatively slower RT and mild decrement in PF during Sham were a consequence of the $30 \mathrm{sec}$ application of tDCS, we compared effects of Sham (30 sec tDCS, see Methods) with no stimulation $(n=4)$. Both Sham and no stimulation elicited comparable trends towards slightly longer RT and weaker PF (Fig. 4; RT:

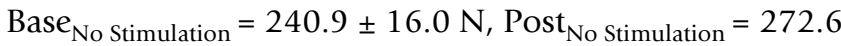
$\pm 31.3 \mathrm{~N}$ and Base $_{\text {Sham }}=257.2 \pm 19.5 \mathrm{~N}$, Post $_{\text {Sham }}=281.3$ $\pm 24.0 \mathrm{~N}$; PF: Base $_{\text {No Stimulation }}=75.8 \pm 22.6$ N, Post $_{\text {No Stim- }}$ ulation $=76.16 \pm 25.1 \mathrm{~N}$ and Base $_{\text {Sham }}=74.8 \pm 25.0 \mathrm{~N}$, PostSham $=73.9 \pm 23.9 \mathrm{~N}$ ) consistent with the independence of these effects from the $30 \mathrm{sec}$ tDCS application during Sham.

\section{Discussions and conclusion}

The main finding of this double-blind sham-controlled cross-over study was that a 20 min period of noninvasive anodal tDCS applied to $\mathrm{M} 1_{\text {affected hemisphere }}$ resulted in tran- 
(A)

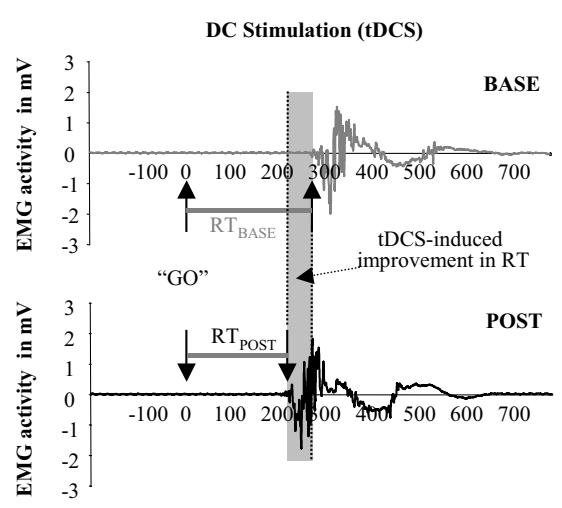

(B)

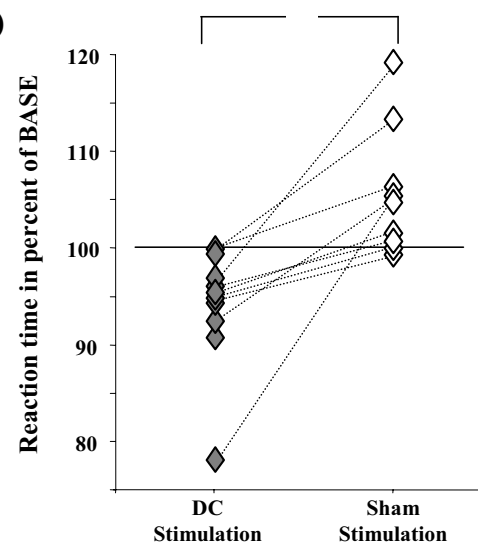

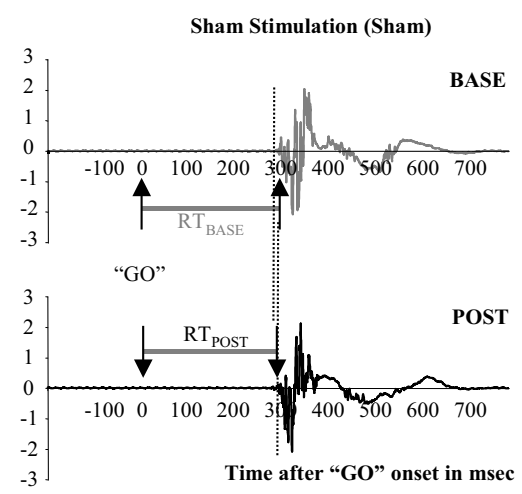

(C)

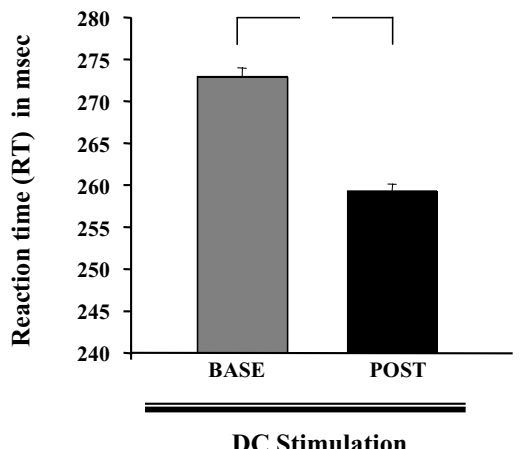

\section{Figure I}

(A) Effects of tDCS on RT (representative trials). RT, measured as the time between the GO-signal and the onset of EMG response, is shown at baseline ( $R T_{\text {Base }}$ ) and post intervention $\left(R T_{\text {Post }}\right)$ in representative trials in the tDCS (left) and Sham (right) sessions. Note the shorter $\mathrm{RT}_{\text {Post }}$ than $\mathrm{RT}_{\text {Base }}$ after $\mathrm{tDCS}$ but not Sham (highlighted in gray). $\mathrm{X}$ axis shows time (msec) and $Y$ axis shows EMG activity $(\mathrm{mV})(B)$ Effects of tDCS on RT (individual subjects) RT after tDCS and Sham relative to baseline (BASE) in all subjects (values $>100$ indicate longer RT, whereas those $<100$ indicate faster RT relative to baseline). Note that RT improved in all subjects with tDCS, while most subjects experienced longer RT with Sham, probably reflecting mild fatigue over the length of the experimental session (see Discussion). Group analysis showed that RT improvements were significantly different from Sham (paired t-test, $p<0.05$ ), an effect present in all subjects (see individual subject connecting lines). (C) Effects of tDCS on RT (group data) tDCS shortened significantly RT (RT Base, paired t-test, $P<0.05$ ). $Y$ axis shows reaction times in msec.

sient improvements in maximal pinch force and reaction times of the paretic hand relative to sham in a group of chronic stroke patients in the absence of measurable nonspecific changes in attention, discomfort or fatigue. These effects were documented in every single patient tested with RT and in all but one with PF. All patients were blind to the intervention type as were investigators testing the endpoint measures.
Previous reports using tDCS and rTMS showed improvements in performance of tasks that mimic activities of daily living performed with the paretic hand after noninvasive cortical stimulation of $\mathrm{M} 1_{\text {affected hemisphere }}[8-11,29]$. Performance of these tasks, like the Jebsen-Taylor test, require complex visuomotor integration and skilled coordination of force production as well as proper management of attentional and motivational resources $[8,13]$. 
(A) Reaction Times

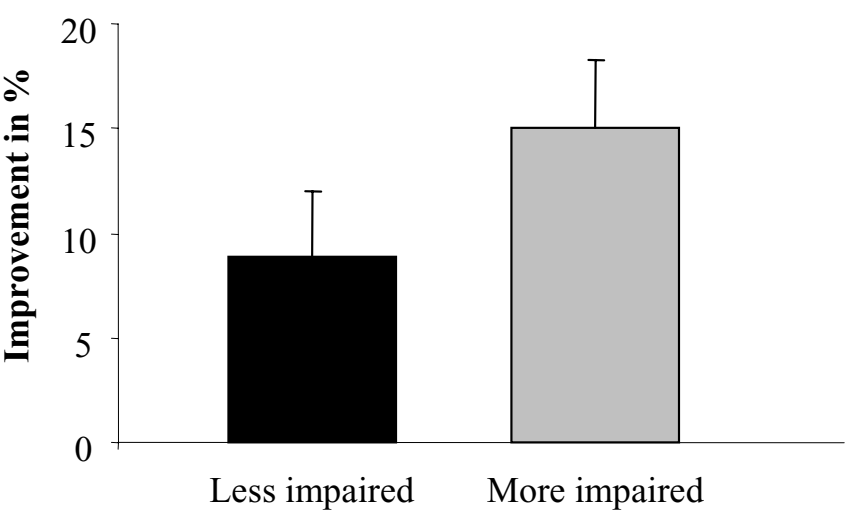

\section{(B) Pinch Forces}

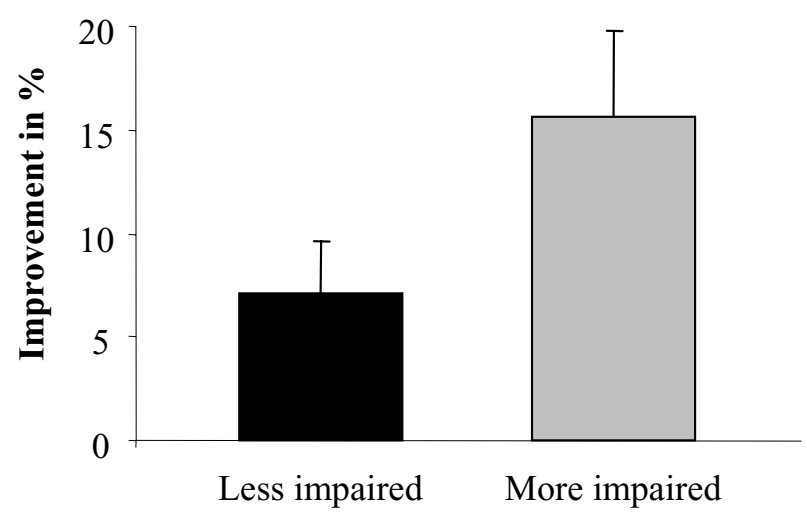

Figure 2

Effects of tDCS and impairment of patients. Patients were stratified in two groups according to their ability to perform skilled ADL-like motor tasks. Less impaired patients $(n=7)$ were able to perform the jebsen-Taylor-Task (JTT) and more impaired patients were not able to perform the JTT. After stratification tDCS-induced improvement of reaction time (A) and pinch force (B) was calculated for each group. Note, that the improvement was larger in the more impaired group.

This study, designed to determine if anodal tDCS over $\mathrm{M} 1_{\text {affected hemisphere }}$ exerted comparable effects over simpler motor tasks, identified improvements in pinch force and reaction times in the paretic hand with this intervention but not with Sham or No stimulation. These effects suggest that anodal tDCS to $M 1_{\text {affected hemisphere }}$ enhanced activity within the primary motor cortex $[8,22,30]$, actively engaged in control of force production and simple visuomotor integration processes [17,18,31-33].

The lack of effects on attention, fatigue and discomfort evidenced by the analysis of visual analog scales, as well as the inability of patients to identify the stimulation and Sham sessions are consistent with results from previous investigations [8,10,23-28]. Furthermore, tDCS was applied over the primary motor cortex, distant from areas involved in modulating attentional and motivational processes (e.g., cingulate cortex, prefrontal cortex, limbic system) $[34,35]$. Interestingly, repetition of both tasks after Sham resulted in a trend towards longer reaction times and weaker pinch force. The finding of this effect in the control experiment with both Sham (30 sec tDCS) and No stimulation (no tDCS) indicates that it was unrelated with the application of $30 \mathrm{sec}$ tDCS during Sham. Most likely, it reflects mild experimental fatigue, subthreshold for detection by the VAS questionnaires $[8,10]$.

Recovery of motor function after stroke starts first with improvements in performance of repetitive, relatively simple motor activities like force production, evolving later to relearning of more complex motor synergies and skillful tasks. It is a common finding that while most chronic stroke patients are able to generate various levels of force, only a fraction of them are able to perform skilled motor tasks like those involved in activities of daily living tested with the Jebsen-Taylor test [36]. Since the ability to control properly force production and visuomotor integration represents a prerequisite to meaningful skilled complex motor activity [37-39], it can be speculated that a first rehabilitative step to promote functional recovery after stroke might focus on reacquisition of these motor primaries. Subsequent training could then utilize these basic skills to train more complex actions, such as proposed in sports and musical practice programs [40]. In this way, motor training of these primaries could be utilized to orchestrate more complex skillful motor tasks [41-43]. The finding that anodal tDCS applied to $M 1_{\text {affected }}$ hemisphere improved force production and a simple visuomotor integration task relative to Sham suggests that these mechanisms could contribute to the behavioral gains reported by anodal tDCS of $M 1_{\text {affected hemisphere }}$ on more complex activities of daily living [8-11]. Of note is that these improvements were present in patients with higher impairment levels unable to perform skilled ADL-like motor tasks (Fig 2).

In summary, the present study provides novel evidence that anodal tDCS of $M 1_{\text {affected hemisphere }}$ may enhance per- 
(A)

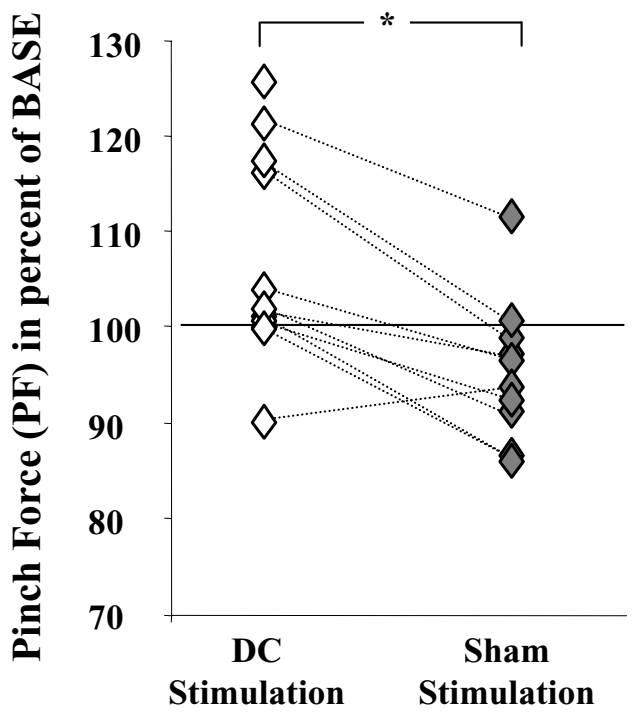

(B)

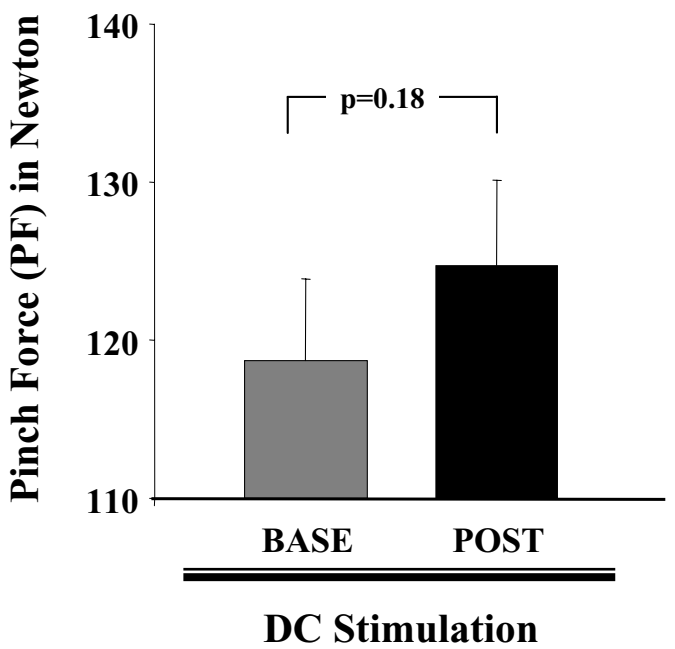

Figure 3

(A) Effects of tDCS on PF (individual subjects). Pinch force after tDCS and Sham relative to baseline (BASE) in all subjects (values $>100$ indicate stronger PF, whereas those $<100$ indicate weaker PF relative to baseline). Note the significant improvement in PF after tDCS compared to Sham, present in all but one patient (paired t-test, $P<0.05$, see also individual subject connecting lines). (B) Effects of tDCS on PF (group data) Group data showed a non-significant trend of increased pinch forces with tDCS (POST) compared to pinch forces during baseline (BASE; paired t-test, $p=0.18$ ).

formance of a wider range of motor tasks than previously thought, some of them relatively simple and mediated predominantly by $\mathrm{M} 1$ function.

\section{Methods}

Patients

We studied eleven patients $(57.0 \pm 16.0$ years; 5 of them females, 9 right-handed, 2 left-handed) with a history of a single mostly subcortical ischemic cerebral infarct, none of whom had a lesion in the primary motor cortex (Table 1 ). They gave written informed consent to participate in the experiment according to the declaration of Helsinki [44,45] and the NINDS Institutional Review Board approved the study protocol. Patients were tested at least 12 months after the stroke $(41.8 \pm 26.4$ months, ranging from 18 to 107 months, Table 1 ). All patients suffered initially from a severe upper arm motor paresis (below MRC grade 2). Motor functions recovered over time and all patients were able to perform the required task properly while some of them remained unable to complete the Jebsen Taylor Test (JTT) test evaluated in previous experi- ments [8]. For detailed clinical information including Fugl-Meyer scale (FMS) [46], Medical Research Council scale (MRC), Modified Ashworth Scale for Grading Spasticity (ASS) [47] and Mini-Mental-Status-Examination (MMSE) [48] please see Table 1. Patients with severe language disturbances, history of severe alcohol or drug abuse, severe depression, or serious cognitive deficits (MMSE <23/30 points) were excluded from participation. One patient did only participate in the tDCS session and one patient did not perform the reaction time task.

\section{Experimental procedures \\ Main experiment}

We tested the effects of anodal tDCS applied to $M 1_{\text {affected }}$ hemisphere on performance of a simple reaction time task (RT) and on pinch force production (PF) in a pseudo-randomized, double-blind Sham-controlled cross-over study design. All patients participated in two sessions (tDCS and Sham separated by $8.2 \pm 1.5$ days (mean \pm SE). Before starting the first session patients got familiarized with the tasks. Half of them started with tDCS and the other half 


\section{(A) Reaction Time Testing}

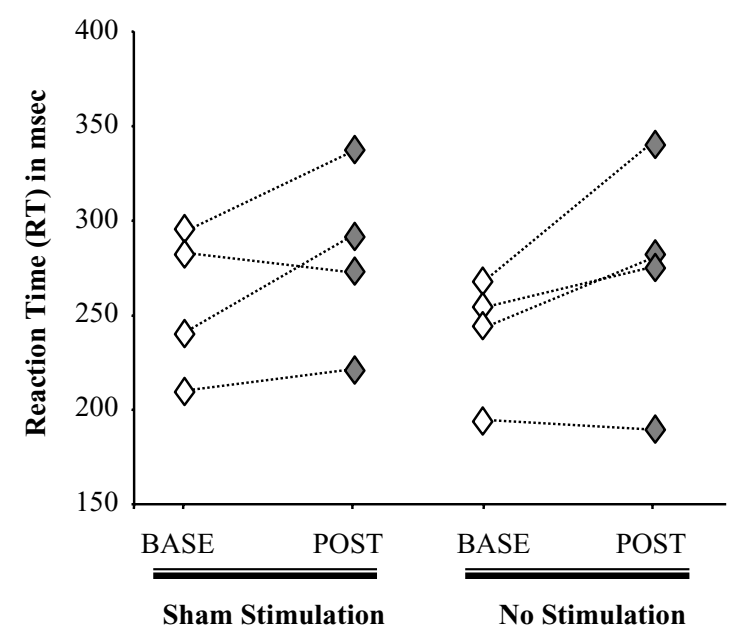

\section{(B) Pinch Force Testing}

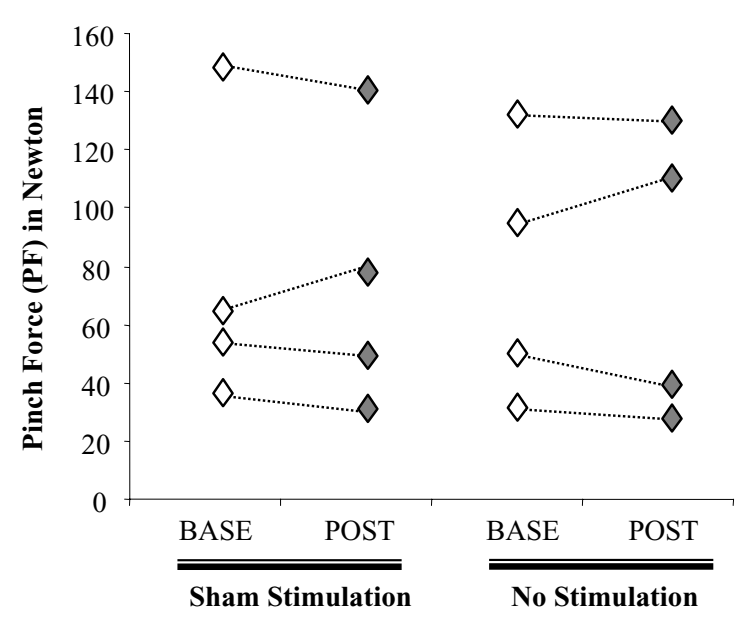

\section{Figure 4}

(A) Effects of Sham stimulation on RT compared to No stimulation. Reaction times were comparable during Sham stimulation and No stimulation with slight slowing of reaction times during POST compared to BASE. (B) Effects of Sham stimulation on PF compared to No stimulation Forces were comparable during Sham stimulation and No stimulation with slight decrease of pinch force during POST compared to BASE.

with Sham. Patients performed three blocks of the RT task and three blocks of the PF task before $\left(\mathrm{RT}_{1}\right.$ to $\mathrm{RT}_{3}$ and $\mathrm{PF}_{1}$ to $\left.\mathrm{PF}_{3}\right)$ and after $\left(\mathrm{RT}_{4}\right.$ to $\mathrm{RT}_{6}, \mathrm{PF}_{4}$ to $\left.\mathrm{PF}_{6}\right)$ anodal tDCS and Sham applied to $M 1_{\text {affected hemisphere. The last measure- }}$ ments were recorded $29.7 \pm 4.2 \mathrm{~min}$ after the end of each intervention. Order of tasks was balanced over subjects and sessions. Instructions to the patients were identical for both Sessions (tDCS and Sham). Questionnaires using visual analog scales (VAS) to evaluate patients' perception of attention (range: $1-10 ; 1=$ no attention, $10=$ highest level of attention) and fatigue (range: $1-10 ; 1=$ highest level of fatigue, $10=$ no fatigue) were determined two times before and two times after tDCS and Sham (see VAS1-4 in Fig 5A). At the end of each session patients were asked to describe their sense of discomfort/pain (range: $1-10 ; 1=$ no discomfort/pain, $10=$ maximal discomfort $/$ pain). The used VAS have good internal consistency, reliability, and objectivity [24-28]. After the end of the study the investigators asked the patients whether they could identify the tDCS and the Sham sessions. All patients but one participated in Session 1 and Session 2. Figure 5A displays a schematic of the experimental design.

In an additional session (control experiment), we evaluated the effects of no stimulation (no tDCS, $n=4$ ) and compared the results with those obtained with Sham. In all sessions patients had the scalp electrodes placed in position and the sessions had a comparable time course.

\section{Reaction time testing}

Patients were seated $60 \mathrm{~cm}$ in front of a 20 inch-monitor with both arms supported by a cushion. They were instructed to focus on the cross in the centre of the screen, and to bend their wrist as quickly as possible in response to the GO-signal (Fig. 5B). Each trial started with a visual warning signal ('Get ready...'), which was followed by a GO-signal at random intervals (2-6 seconds). Each block consisted of 23 wrist flexion trials. The first three trials of every block were used as practice trials and were not included in the analysis. Electromyogram (EMG) was recorded from silver-silver chloride electrodes positioned in a belly tendon montage on the skin overlying the Flexor Carpi Radialis muscle $(50 \mathrm{~Hz}-2 \mathrm{kHz}$, sampling rate $5 \mathrm{kHz}$ ) from a Counterpoint Electromyograph (Dantec Electronics Sklovlunde, Denmark). The reaction time (RT in msec) was defined as the time interval between the GO-signal and the onset of the EMG-burst (Fig. 5B, 1A). Patients didn't receive any feedback about their performance. Reaction times were analyzed by an investigator blinded towards the INTERVENTION type (Sham, tDCS) and 
Table I:

\begin{tabular}{|c|c|c|c|c|c|c|c|c|}
\hline \multirow[t]{2}{*}{ Patient } & \multirow[t]{2}{*}{ Age } & \multirow[t]{2}{*}{ Sex } & \multirow[t]{2}{*}{ Time after stroke (mo) } & \multirow[t]{2}{*}{ Handedness (EDS) } & \multirow[t]{2}{*}{ MMSE } & \multicolumn{3}{|c|}{ Motor Function } \\
\hline & & & & & & MRC & FMS & ASS \\
\hline A & 35 & $f$ & 72 & Right $(48 / 50)$ & $30 / 30$ & 4.0 & .85 & 1 \\
\hline B & 41 & $\mathrm{~m}$ & 48 & Left $(12 / 50)$ & $30 / 30$ & 4.80 & .95 & 2 \\
\hline $\mathrm{C}$ & 72 & $f$ & 34 & Right $(46 / 50)$ & $29 / 30$ & 4.80 & .96 & 0 \\
\hline $\mathrm{D}$ & 44 & $f$ & 24 & Right $(48 / 50)$ & $29 / 30$ & 4.90 & .99 & 0 \\
\hline$E$ & 38 & $f$ & 31 & Right (49/50) & $29 / 30$ & 4.90 & .99 & 0 \\
\hline $\mathrm{F}$ & 61 & $\mathrm{~m}$ & 42 & Right $(49 / 50)$ & $28 / 30$ & 4.50 & .79 & 3 \\
\hline G & 72 & $\mathrm{~m}$ & 23 & Right $(46 / 50)$ & $30 / 30$ & 4.70 & .91 & $1+$ \\
\hline $\mathrm{H}$ & 61 & $f$ & 38 & Right (42/50) & $29 / 30$ & 3.80 & .82 & 3 \\
\hline I & 66 & $\mathrm{~m}$ & 23 & Right (49/50) & $28 / 30$ & 4.90 & .95 & 0 \\
\hline$J$ & 54 & $\mathrm{~m}$ & 18 & Right $(46 / 50)$ & $28 / 30$ & 4 & .81 & 2 \\
\hline $\mathrm{K}$ & 84 & $\mathrm{~m}$ & 107 & Right (47/50) & $29 / 30$ & 4.80 & .96 & 0 \\
\hline
\end{tabular}

ASS = Ashworth Spasticity Score; EDS = Edinburgh-Handedness-Scale; FMS = Fugl-Meyer-Scale (presented in relative terms of the maximum of points [66]); MMSE = Mini-Mental-Status-Examination; MRC = Scale to determine strength by the Medical Research Council (mean MRC value of the tested muscles).

towards TIME (Base, Post). Trials with EMG activity in the rest period before the GO-signal were excluded from analysis.

\section{Pinch force testing}

Patients were seated in an armchair with both arms relaxed. Maximal pinch force of the paretic hand was measured according to a protocol with good validity and test-retest reliability $[49,50]$. Patients held the arm of a dynamometer between the lateral aspect of the middle phalanx of the index finger and the thumb pad of the paretic hand and were instructed to squeeze the gauge as hard as they could for 1-3 seconds (Fig. 4C). Patients didn't receive any feedback about their performance. Nine muscle strength measurements were averaged in each block. Maximal pinch force (PF) was elicited by pinching the gauge between the thumb and the index finger of the paretic hand. Trials in which pinch force was produced during the rest period where excluded from analysis.

\section{Noninvasive anodal tDCS}

Anodal tDCS was delivered for 20 minutes in the tDCS session and for up to 30 seconds in the Sham session using a Phoresor ${ }^{\circledast}$ II Auto (Model No. PM850, IOMED ${ }^{\circledR}$, Salt Lake City, Utah 84120 USA) through two gel-sponge electrodes (TransQE from IOMED ${ }^{\circledR}$, surface area was 25 $\mathrm{cm}^{2}$ for each electrode) embedded in a saline-soaked solution. For both interventions (tDCS and Sham) current was increased in a ramp-like fashion at the onset of the stimulation $[8,21]$ eliciting a transient tingling, burning sensation on the scalp that disappeared over seconds, consistent with previous reports $[8,21,23]$. Current (1 $\mathrm{mA}$ ) remained on for 20 minutes in the tDCS session and for up to 30 seconds in the Sham session. At the end of the session, tDCS was turned off slowly over a few seconds, a procedure that does not elicit additional perceptions $[8,21]$.

\section{Blinding procedure}

The patients and the investigator performing motor testing and data analysis were blinded to the type of intervention (tDCS or Sham) as described previously $[8,10,23]$. The tDCS device remained out of the patients' view at all times. Another unblinded investigator's sole participation in the study consisted in administering the interventions. Participants were explicitly asked after the experiments whether they are able to determine which of the experimental session was "real" stimulation and which one was "not real, sham" stimulation.

\section{Electrode positions}

In seven patients, the anode was positioned on the projection of the hand knob area [51] of the primary motor cortex of the affected hemisphere on the patient's scalp by using coregistered MRI for neuronavigation (Brainsight ${ }^{\circledR}$ ). In 4 patients in whom MRI was not available at the time of testing, the anode was centered on the optimal scalp position for activation of the paretic First Dorsal Interosseus (FDI) muscle using an 8-shaped TMS Magstim coil, a procedure that matches the projection of the anatomical hand knob [52]. The cathode was placed on the skin overlying the contralateral supraorbital region.

\section{Data analysis}

Reaction time and pinch force data were normally distributed as evaluated by Kolmogorov-Smirnov test. For statistical analysis the three baseline ( $\mathrm{RT}_{1}$ to $\mathrm{RT}_{3}, \mathrm{PF}_{1}$ to $\mathrm{PF}_{3}$ ) and the three post intervention measurements $\left(\mathrm{RT}_{4}\right.$ to $\mathrm{RT}_{6}, \mathrm{PF}_{4}$ to $\mathrm{PF}_{6}$ ) were pooled (Fig 5A). Repeated measures ANOVA $\left(\right.$ ANOVA $_{R M}$ ) was used to evaluate the effects of 
(A)

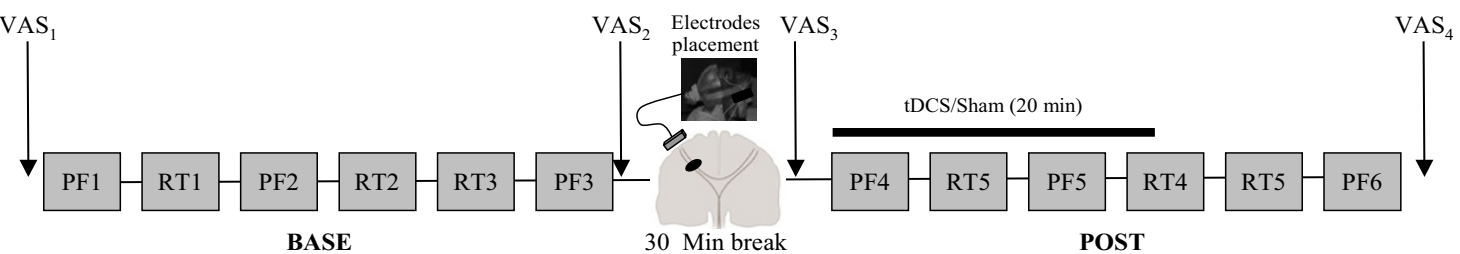

(B)

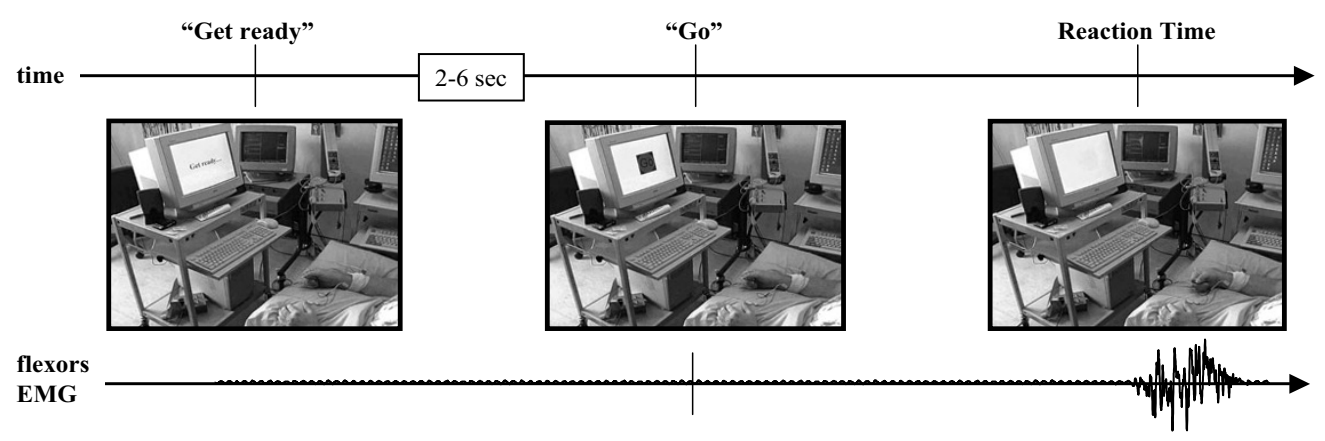

(C)

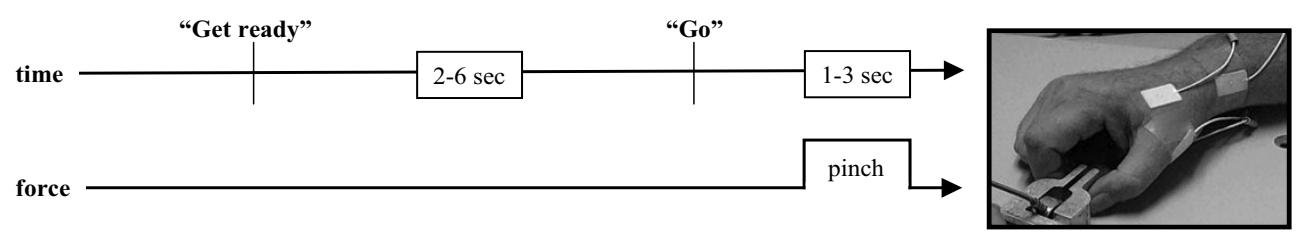

\section{Figure 5}

(A) Experimental design of a single session. In this study we used a double-blind, crossover study design with 2 sessions (tDCS and Sham). Half of the patients started with tDCS and the other half with Sham. Each session started with baseline determinations (BASE) of reaction times $\left(\mathrm{RT}_{I_{-3}}\right)$ and pinch force $\left(\mathrm{PF}_{\mathrm{I}_{-3}}\right)$, followed by a 30 min break in which tDCS electrodes were placed. Then $\mathrm{tDCS}$ or Sham was applied in a counterbalanced double-blind design followed by post intervention measures $\left(\mathrm{RT}_{4-6}\right.$ and $\left.\mathrm{PF}_{4-6}\right)$. All patients described their level of attention toward the task (range: $I-10$; $I=$ no attention, $10=$ highest level of attention) and their perception of fatigue (range: I-I0; I = highest level of fatigue, $10=$ no fatigue) four times in each session $\left(\mathrm{VAS}_{1}-\mathrm{VAS}_{4}\right)$, and their sense of discomfort/pain after each session ended (range: I-I0; I = no discomfort/pain, I0 = maximal discomfort/pain) using visual analog scales (VAS) that have good internal consistency, reliability, and objectivity [24, $25,27,28]$. Instructions to the patients were identical for all Sessions. In 4 patients an additional session was performed as a control experiment to evaluate the effects of No Stimulation compared to Sham stimulation. (B) Reaction Time Testing during a Visuo-Motor Task Patients were seated in a comfortable armchair and were instructed to focus attention on a cross in the centre of a video screen, and to bend their wrist as quickly as possible in response to a GO-signal presented on the screen. Trials were started with a visual warning signal ('Get ready'), followed by a GO-signal at random intervals (2-6 seconds). Blocks consisted of 23 wrist flexion trials with the first three trials of a block used as practice trials. These trials were not included in the analysis. EMG was recorded from silver-silver chloride electrodes positioned in a belly tendon montage on the skin overlying the Flexor Carpi Radialis muscle. Reaction times (RT) were defined as the time interval between the GO-signal and the onset of the EMG-burst in the Flexor Carpi Radialis muscle. Patients didn't receive any feedback about there performance. (C) Pinch Force Testing Task Patients were seated in a comfortable armchair with both arms relaxed. Maximal pinch strength of the paretic hand was measured according to a protocol with good validity and test-retest reliability [49, 50]. Patients held the arm of a dynamometer between the lateral aspect of the middle phalanx of the index finger and the thumb pad. Trials were started with a warning signal ('Get ready'), followed by a GO-signal at random intervals (2-6 seconds). Patients were instructed to squeeze the gauge as hard as they could for I-3 seconds after GO-signal. Patients didn't receive any feedback about there performance. Blocks consisted of nine consecutive trials. 
INTERVENTION $_{\text {(tDCS, Sham) }}$ and TIME (Base, Post) $_{\text {on RT and }}$ on PF. Paired t-tests were used to evaluate reports of discomfort/pain. For the control experiment paired t-tests were used to compare the No stimulation with the Sham condition. Non-parametric Friedman test was used to evaluate the effects of INTERVENTION ${ }_{(\mathrm{tDCS}, \text { Sham) }}$ on attention and fatigue, which were not normally distributed. Conditioned on significant $\mathrm{p}$-values ( $\mathrm{p}<0.05)$, post-hoc testing was performed and corrected for multiple comparisons when necessary. All data are expressed as mean $\pm \mathrm{SE}$.

\section{Abbreviations}

ADL $=$ Activities of daily living

ASS = Modified Ashworth Scale for Grading Spasticity

Base $_{\mathrm{tDCS}}=$ Baseline before tDCS as intervention

Base $_{\text {Sham }}=$ Baseline before Sham as intervention

Base $_{\text {No Stimulation }}=$ Baseline before No Stimulation as intervention

FMS = Fugl-Meyer scale

JTT = Jebsen-Taylor Hand Function Test

$\mathrm{M} 1$ = Primary motor cortex

$\mathrm{M} 1_{\text {affected hemisphere }}=$ Motor cortex of the affected hemisphere

MMSE = Mini-Mental-Status-Examination

MRC $=$ Medical Research Council scale

$\mathrm{PF}=$ Pinch force

PFT $=$ Pinch force testing

Post $_{\mathrm{tDCS}}=$ After tDCS as intervention

Post $_{\text {Sham }}=$ After Sham as intervention

Post $_{\text {No Stimulation }}=$ After No Stimulation as intervention

$\mathrm{RT}=$ Reaction time

rTMS = Repetitive transcranial magnetic stimulation

RTT $=$ Reaction time testing

tDCS $=$ Transcranial DC stimulation

VAS $=$ Visual analog scale

\section{Competing interests}

The author(s) declare that they have no competing interests.

\section{Authors' contributions}

FH, LC, CG, PC, AF, PG participated in the design of the study; FH, PG, PC, AF, BV participated in acquisition and analysis of data; all authors participated in the interpretation of the data; FH, LC drafted the manuscript; all authors read and approved the manuscript.

Part of the data from one of these patients has been published as a case report.

\section{Acknowledgements}

This research was supported by the intramural research program of NINDS, NIH, a grant from the Alexander von Humboldt Foundation (Feodor-Lynen) to F. Hummel and by the Rehabilitation Medicine Scientist Training Program (RMSTP), grant number: 5K I2HD00 1097, to P. Celnik.

\section{References}

I. Gresham GE, Fitzpatrick TE, Wolf PA, McNamara PM, Kannel WB, Dawber TR: Residual disability in survivors of stroke--the Framingham study. N Engl J Med 1975, 293:954-956.

2. Jorgensen HS, Nakayama H, Raaschou HO, Vive-Larsen J, Stoier M, Olsen TS: Outcome and time course of recovery in stroke. Part II: Time course of recovery. The Copenhagen Stroke Study. Arch Phys Med Rehabil 1995, 76:406-4I2.

3. Jorgensen HS, Nakayama H, Raaschou HO, Vive-Larsen J, Stoier M, Olsen TS: Outcome and time course of recovery in stroke. Part I: Outcome. The Copenhagen Stroke Study. Arch Phys Med Rehabil 1995, 76:399-405.

4. Kolominsky-Rabas PL, Weber M, Gefeller O, Neundoerfer B, Heuschmann PU: Epidemiology of ischemic stroke subtypes according to TOAST criteria: incidence, recurrence, and long-term survival in ischemic stroke subtypes: a populationbased study. Stroke 2001, 32:2735-2740.

5. Kolominsky-Rabas PL, Heuschmann PU: [Incidence, etiology and long-term prognosis of stroke]. Fortschr Neurol Psychiatr 2002, 70:657-662.

6. Kwakkel G, Kollen BJ, van der Grond J, Prevo AJ: Probability of regaining dexterity in the flaccid upper limb: impact of severity of paresis and time since onset in acute stroke. Stroke 2003, 34:2181-2186.

7. Lai SM, Studenski S, Duncan PW, Perera S: Persisting consequences of stroke measured by the Stroke Impact Scale. Stroke 2002, 33:1840-1844.

8. Hummel F, Celnik P, Giraux P, Floel A, Wu WH, Gerloff C, Cohen LG: Effects of non-invasive cortical stimulation on skilled motor function in chronic stroke. Brain 2005, I 28:490-499.

9. Hummel F, Cohen LG: Improvement of motor function with noninvasive cortical stimulation in a patient with chronic stroke. Neurorehabil Neural Repair 2005, 19:14-19.

10. Fregni F, Boggio PS, Mansur CG, Wagner T, Ferreira MJ, Lima MC, Rigonatti SP, Marcolin MA, Freedman SD, Nitsche MA, Pascual-Leone $A$ : Transcranial direct current stimulation of the unaffected hemisphere in stroke patients. Neuroreport 2005, I 6: I55 I-I 555.

II. Khedr EM, Ahmed MA, Fathy N, Rothwell JC: Therapeutic trial of repetitive transcranial magnetic stimulation after acute ischemic stroke. Neurology 2005, 65:466-468.

12. Hummel FC, Cohen LG: Non-invasive brain stimulation: a new strategy to improve neurorehabilitation after stroke? Lancet Neurol 2006, 5:708-712.

13. Jebsen RH, Taylor N, Trieschmann RB, Trotter MJ, Howard LA: An objective and standardized test of hand function. Arch Phys Med Rehabil 1969, 50:311-319.

14. Rao SM, Harrington DL, Haaland KY, Bobholz JA, Cox RW, Binder JR: Distributed neural systems underlying the timing of movements. J Neurosci 1997, I7:5528-5535. 
15. Haaland KY, Elsinger CL, Mayer AR, Durgerian S, Rao SM: Motor sequence complexity and performing hand produce differential patterns of hemispheric lateralization. J Cogn Neurosci 2004, I 6:62I-636.

16. Hummel F, Saur R, Lasogga S, Plewnia C, Erb M, Wildgruber D, Grodd W, Gerloff C: To act or not to act. Neural correlates of executive control of learned motor behavior. Neuroimage 2004, 23:|39|-|40|.

17. Ashe J: Force and the motor cortex. Behav Brain Res 1997, 87:255-269.

18. Georgopoulos AP, Ashe J, Smyrnis N, Taira M: The motor cortex and the coding of force. Science 1992, 256:1692-1695.

19. Maier MA, Bennett KM, Hepp-Reymond MC, Lemon RN: Contribution of the monkey corticomotoneuronal system to the control of force in precision grip. I Neurophysiol 1993, 69:772-785.

20. Nowak DA, Voss M, Huang YZ, Wolpert DM, Rothwell JC: Highfrequency repetitive transcranial magnetic stimulation over the hand area of the primary motor cortex disturbs predictive grip force scaling. Eur J Neurosci 2005, 22:2392-2396.

21. Nitsche MA, Liebetanz D, Antal A, Lang N, Tergau F, Paulus W: Modulation of cortical excitability by weak direct current stimulation--technical, safety and functional aspects. Suppl Clin Neurophysiol 2003, 56:255-276.

22. Nitsche MA, Paulus W: Excitability changes induced in the human motor cortex by weak transcranial direct current stimulation. J Physiol 2000, 527 Pt 3:633-639.

23. Gandiga PC, Hummel FC, Cohen LG: Transcranial DC stimulation (tDCS): A tool for double-blind sham-controlled clinical studies in brain stimulation. Clin Neurophysiol 2006, I I 7:845-850

24. Chibnall JT, Tait RC: Pain assessment in cognitively impaired and unimpaired older adults: a comparison of four scales. Pain 200I, 92: 173-186.

25. Floel A, Nagorsen U, Werhahn KJ, Ravindran S, Birbaumer N, Knecht $\mathrm{S}$, Cohen LG: Influence of somatosensory input on motor function in patients with chronic stroke. Ann Neurol 2004, 56:206-2I2.

26. Reisine S, Fifield J, Walsh SJ, Feinn R: Do employment and family work affect the health status of women with fibromyalgia? J Rheumatol 2003, 30:2045-2053.

27. Folstein MF, Luria R: Reliability, validity, and clinical application of the Visual Analogue Mood Scale. Psychol Med 1973, 3:479-486.

28. Gracely RH: Pain measurement. Acta Anaesthesiol Scand 1999, 43:897-908.

29. Kim YH, You SH, Ko MH, Park JW, Lee KH, Jang SH, Yoo WK, Hallett M: Repetitive transcranial magnetic stimulation-induced corticomotor excitability and associated motor skill acquisition in chronic stroke. Stroke 2006, 37:|47|-|476.

30. Nitsche MA, Seeber A, Frommann K, Klein CC, Rochford C, Nitsche MS, Fricke K, Liebetanz D, Lang N, Antal A, Paulus W, Tergau F: Modulating parameters of excitability during and after transcranial direct current stimulation of the human motor cortex. J Physiol 2005.

31. Georgopoulos AP, Grillner S: Visuomotor coordination in reaching and locomotion. Science 1989, 245:|209-1210.

32. Graziano MS, Taylor CS, Moore T, Cooke DF: The cortical contro of movement revisited. Neuron 2002, 36:349-362.

33. Rizzolatti G, Craighero L: The mirror-neuron system. Annu Rev Neurosci 2004, 27:169-192.

34. Thiel CM, Zilles K, Fink GR: Cerebral correlates of alerting, orienting and reorienting of visuospatial attention: an eventrelated fMRI study. Neuroimage 2004, 2 1:3 18-328.

35. Small DM, Gitelman DR, Gregory MD, Nobre AC, Parrish TB, Mesulam MM: The posterior cingulate and medial prefrontal cortex mediate the anticipatory allocation of spatial attention. Neuroimage 2003, 18:633-64I.

36. Kraft GH, Fitts SS, Hammond MC: Techniques to improve function of the arm and hand in chronic hemiplegia. Arch Phys Med Rehabil 1992, 73:220-227.

37. Shadmehr R, Wise SP: Computational Neurobiology of Reaching and Pointing. A Foundation for Motor Learning. Cambridge, MA, MIT Press; 2005.

38. Inui $\mathrm{N}$, Ichihara $\mathrm{T}$ : Independence of timing and force control during finger-tapping sequences by pianists. Percept Mot Skills 200I, 93:556-558.
39. Inui $\mathrm{N}$, Ichihara $\mathrm{T}$ : Comparison of the relation between timing and force control during finger-tapping sequences by pianists and non pianists. Motor Control 200I, 5:385-398.

40. Handford C, Davids K, Bennett S, Button C: Skill acquisition in sport: some applications of an evolving practice ecology. J Sports Sci 1997, 15:621-640.

4I. Inui N, Katsura Y: Development of force control and timing in a finger-tapping sequence with an attenuated-force tap. Motor Control 2002, 6:333-346.

42. Loseby PN, Piek JP, Barrett NC: The influence of speed and force on bimanual finger tapping patterns. Hum Mov Sci 200I, 20:53I-547.

43. d'Avella A, Bizzi E: Shared and specific muscle synergies in natural motor behaviors. Proc Natl Acad Sci U S A 2005 , 102:3076-308|

44. association TWM: [http://www.wma.net/e/policy/b3.htm].

45. World Medical Association declaration of Helsinki. Recommendations guiding physicians in biomedical research involving human subjects. Jama 1997, 277:925-926.

46. Fugl-Meyer AR, Jaasko L, Leyman I, Olsson S, Steglind S: The poststroke hemiplegic patient. I. a method for evaluation of physical performance. Scand J Rehabil Med 1975, 7:|3-31.

47. Bohannon RW, Smith MB: Interrater reliability of a modified Ashworth scale of muscle spasticity. Phys Ther 1987, 67:206-207.

48. Folstein MF, Folstein SE, McHugh PR: "Mini-mental state". A practical method for grading the cognitive state of patients for the clinician. J Psychiatr Res 1975, I 2: I89-198.

49. Mathiowetz V, Kashman N, Volland G, Weber K, Dowe M, Rogers S: Grip and pinch strength: normative data for adults. Arch Phys Med Rehabil 1985, 66:69-74.

50. Mathiowetz V, Weber K, Volland G, Kashman N: Reliability and validity of grip and pinch strength evaluations. J Hand Surg [Am] 1984, 9:222-226.

5I. Yousry TA, Schmid UD, Alkadhi H, Schmidt D, Peraud A, Buettner A, Winkler P: Localization of the motor hand area to a knob on the precentral gyrus. A new landmark. Brain 1997, 120 ( Pt I): $14 \mid-157$

52. Hallett M: Transcranial magnetic stimulation and the human brain. Nature 2000, 406:147-150.

Publish with Biomed Central and every scientist can read your work free of charge

"BioMed Central will be the most significant development for disseminating the results of biomedical research in our lifetime. "

Sir Paul Nurse, Cancer Research UK

Your research papers will be:

- available free of charge to the entire biomedical community

- peer reviewed and published immediately upon acceptance

- cited in PubMed and archived on PubMed Central

- yours - you keep the copyright 